\title{
Developments of crawler steering gearbox for combine harvester straight forward and steering in situ
}

\author{
Zhong Tang ${ }^{1,2}$, Haotian Zhang ${ }^{1,2}$, Hongchang $\mathrm{Li}^{1,2}$, Yaoming $\mathrm{Li}^{1,2}$, Zhao Ding ${ }^{1,2}$, Jinsong Chen ${ }^{1,2}$ \\ (1.School of Agricultural Equipment Engineering, Jiangsu University, Zhenjiang 212013, Jiangsu, China; 2. Key Laboratory of Modern \\ Agricultural Equipment and Technology of Ministry of Education, Jiangsu University, 212013 Zhenjiang, Jiangsu, China)
}

\begin{abstract}
Soil compaction and accumulation are caused by crawler steering. Soil characteristics would affect the ability of crawler straight forward and steering in situ. This paper studied the principle of straight forward steering and steering in situ mode of traditional unilateral brake steering gearbox of a crawler combine harvester. Then a positive and negative steering gearbox model was developed and processed. The performance of positive and negative steering gearbox was analyzed by performing two steering modes on soil compaction effect. Results showed that the positive and negative steering gearboxes can achieve three operating modes, such as straight forward, unilateral brake steering, and positive and negative steering in situ. The positive and negative steering in situ was smooth and without soil accumulation phenomenon. When the crawlers center distance, crawler grounding length, crawler width were $1150 \mathrm{~mm}, 1620 \mathrm{~mm}$ and $450 \mathrm{~mm}$ respectively, the rolling area and the scratch free area of positive and negative steering gearbox were $5.37 \mathrm{~m}^{2}$ and $0.36 \mathrm{~m}^{2}$ respectively. However, the rolling area and the scratch free area produced by unilateral brake steering gearbox were $13.92 \mathrm{~m}^{2}$ and $1.88 \mathrm{~m}^{2}$ respectively, which was 8.55 $\mathrm{m}^{2}$ larger than that of positive and negative steering gearbox. The crawler with positive and negative steering gearbox has minor damage to paddy soil. This research can provide a theoretical basis for the smooth steering in situ and structural optimization of the crawler steering gearbox.
\end{abstract}

Keywords: steering gearbox, rolling soil track, steering in situ, rolling and scraping, shaft and gear DOI: $10.25165 /$ j.ijabe.20201301.3957

Citation: Tang Z, Zhang H T, Li H C, Li Y M, Ding Z, Chen J S. Developments of crawler steering gearbox for combine harvester straight forward and steering in situ. Int J Agric \& Biol Eng, 2020; 13(1): 120-126.

\section{Introduction}

The crawler of rice combine harvester always goes forward and turning in wet field. Due to the large touching surface with soil field, the pressure between the field and track would be smaller than that of wheeled vehicle ${ }^{[1,2]}$. The wheeled chassis is easily sunken in the field and does not work properly ${ }^{[3,4]}$. It was found that crawler of combine harvester was more apt to work in field with high moisture ${ }^{[5]}$. For the sake of steady running, rubber tracked vehicles were commonly applied in harvesters to cope with the difficulty of high moisture and low carrying capacity of paddy soil $^{[6]}$. Soil compaction resulted from mechanical rolling was one of the major problems in land reclamation ${ }^{[7]}$. There were many factors that influenced soil compaction apart from soil properties, mechanical pressure, soil layer, etc. But crawler can effectively reduce mechanical compaction on wet soil.

The traditional crawler of combine harvester was unilateral brake and unilateral steering. This steering method could result in

\section{Received date: 2017-11-07 Accepted date: 2019-09-11}

Biographies: Haotian Zhang, Master candidate, research interest: intelligent harvesting machinery, Email: 398386781@qq.com; Hongchang Li, PhD, Associate Professor, research interests: intelligent harvesting machinery, Email: 342636591@qq.com; Yaoming Li, PhD, Professor, research interests: intelligent harvesting machinery, Email: ymli@ujs.edu.cn; Zhao Ding, Doctoral student, research interests: intelligent harvesting machinery, Email: 416365960@qq.com; Jinsong Chen, Master candidate, research interest: intelligent harvesting machinery, Email: 1271807138@qq.com.

*Corresponding author: Zhong Tang, PhD, Associate Researcher, research interests: intelligent harvesting machinery, School of Agricultural Equipment Engineering, Jiangsu University, Zhenjiang 212013, Jiangsu, China. Tel: +8613921585015, Email: tangzhong2012@126.com. field soil damage with crawling sinking into soft soil ${ }^{[8,9]}$. The status quo of traditional crawler steering is shown in Figure 1. The steering radius was very large with a seriously destroyed soil layer. The inner crawler caused serious obstructing soil mound with larger power consumption. The crawler would slip in rice field with seriously obstructing soil.

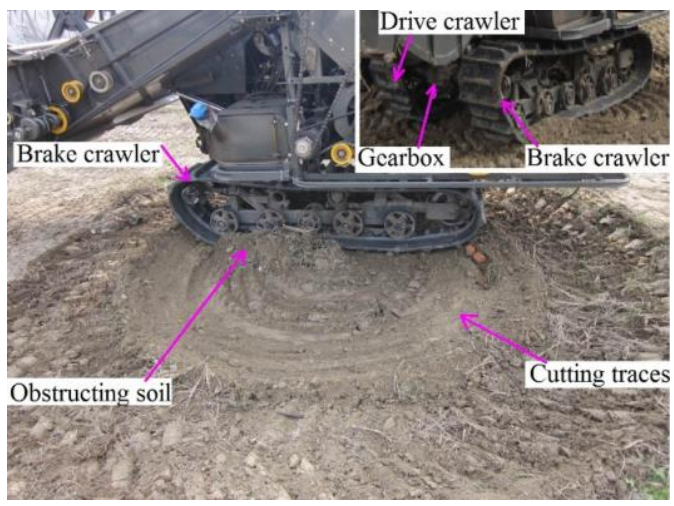

Figure 1 Crawler unilateral brake steering status with $360^{\circ}$ in dry soil

The unilateral brake steering mode was widely applied in crawler harvester. Currently, the unilateral brake steering gearbox of combine harvester can go straight forward, back and steer. But this steering way often led to soil accumulation. When the steering angle exceeded $180^{\circ}$, steering became difficult and needed to be repeated multiple times ${ }^{[10]}$. The existing unilateral brake system in combine harvester has turned to a large radius and had a serious impact on soft soil. Unilateral brake steering has caused the existing crawler combine harvester to be inflexible in the field and prone to crawling and other issues. In order to resolve these 
problems, many scholars have carried out much research on soil properties, steering structure, ground viscosity resistance, steering control, etc ${ }^{[11-13]}$.

In order to investigate the steady state steering performances of the crawler, the influence factors of steering power ratio, steering radius, skid ratio and steering coefficient have been researched ${ }^{[14]}$. Calculating and experimental methods of steering power ratio for tracked vehicles of differential steering were presented and tested by $\mathrm{Chi}$ et $\mathrm{al}^{[15]}$. Terramechanics were fundamental for the development of crawler combine harvester. The physical properties of surface soil have been lucubrated by some researchers ${ }^{[16]}$. Plate sinkage test was used to determine the soil parameters of the steering experiment ground. Track tension on ground pressure distribution affects crawler steering. The smaller steering radius of steering mechanism needs to design for improving steering performance.

For improving the steering performance of a smaller steering radius, a control strategy using dual electric motor torque control on the basis of pivot steering kinetic model was investigated ${ }^{[17]}$. The simulation and prototype test showed that it was feasible to use the way of positive inversion of two hydraulic motors to achieve pivot steering with a small steering radius ${ }^{[18]}$. So far, the existing research of steering in situ was mainly concentrated in the military tank crawler. A small steering radius of dual hydraulic chassis also has been developed. Small radius hydraulic drive steering crawlers were mainly concentrated on ground, hard road and mountain. These related research results were rarely applied in agricultural paddy field. The manufacturing costs of electronic control steering or pure hydraulic drive steering system were expensive for crawler chassis. It was also difficult to adapt to wet, complex soft soil paddy fields.

This paper developed a positive and negative steering gearbox, which could travel and steering in situ. The steering in situ was smooth and without soil cutting phenomenon. The steering radius and steering trajectory were compared between positive and negative steering gearbox (Abbreviated: PNS gearbox) and unilateral brake steering gearbox (Abbreviated: UBS gearbox). The structural parameters of steering gear in situ were obtained. Crawler steering trajectories and soil surface features were used to measure the steering performance of PNS.

\section{Material and methods}

\subsection{Traditional unilateral brake gearbox}

The straight forward and steering of crawler were determined by driving mode. The traditional unilateral brake crawler steering gearbox contained hydraulic static transmission (Abbreviated: HST) and steering gearbox. The crawler steering gearbox on combine harvester was Dragon 4LZ-2.3 (Manufactured by Jiangsu World Agricultural Machinery Co., Ltd.), which is shown in Figure 2.

According to Figure 2, the driving force route of unilateral brake steering gearbox was along the Engine to gear shift device. In order to achieve straight forward and steering, there were complex reversing gear systems. Power was input into HST from Engine and then the input speed was steplessly adjusted by HST. In the UBS gearbox, the 3 stalls gear could achieve three kinds of speed transformation.

Unilateral brake steering gear position was controlled by manual operation. The straight driving and braking were achieved by clutching gear shaft. The internal structural and principle of the UBS gearbox are shown in Figure 3.
HST is an intermediary that connects the power transmission between the engine and the UBS steering gearbox. Then gear shift device achieves third stall gear speed adjustment. HST consists of a hydraulic pump and a hydraulic motor. Engine transmitted power to HST hydraulic pump. The Engine's mechanical energy was converted into hydraulic energy. The forward and reverse of HST output shaft were controlled by adjusting the hydraulic pump output hydraulic oil flow. The Rated output speed of HST was 0-2600 r/min.

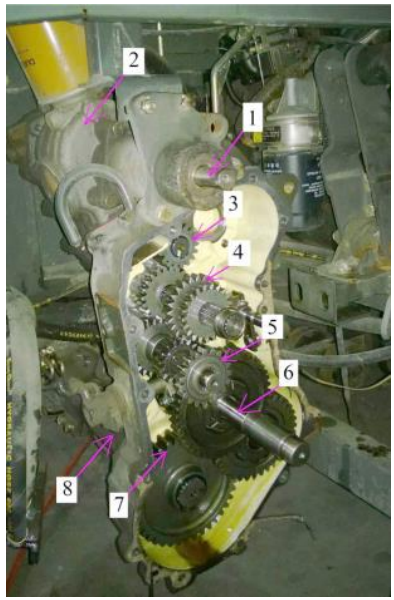

1. Power input shaft 2. HST 3. HST output gear 4. Shift gear 5. Idler shaft 6. Clutch gear shaft 7. Drive shaft gear. 8. Crawler drive shaft

Figure 2 Internal gear transmission pattern of unilateral brake steering gearbox

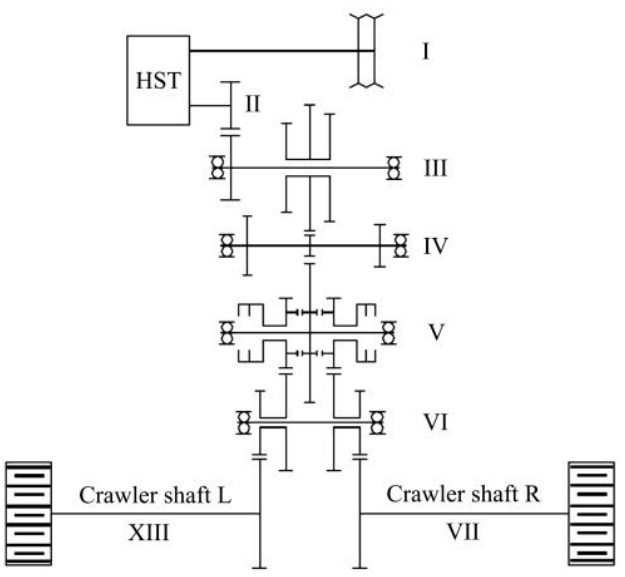

Note: I: Power input shaft and pulley of HST; II: HST output gear and gear; III Shift shaft and gear; IV: Idler shaft and gear; V: Clutch shaft and gear; VI: Brake shaft and gear; VII: Crawler shaft II and crawler R; VIII: Crawler shaft and crawler L.

Figure 3 Structural of UBS steering gearbox

Combine harvester has three stall gears. The forward speeds of the first gear, second gear and third gear are $0-1 \mathrm{~m} / \mathrm{s}, 0-1.5 \mathrm{~m} / \mathrm{s}$ and $0-2 \mathrm{~m} / \mathrm{s}$, respectively. The crawler drive wheel radius of unilateral brake steering is $0.12 \mathrm{~m}$. The three stall gears parameters of unilateral brake steering were tested. The three stall gears parameters are shown in Table 1.

Table 1 Three stall gears parameters of UBS gearbox

\begin{tabular}{cccc}
\hline Stall gear & $\begin{array}{c}\text { Forward speeds } \\
/ \mathrm{m} \cdot \mathrm{s}^{-1}\end{array}$ & $\begin{array}{c}\text { Rotational speed } \\
/ \mathrm{r} \cdot \mathrm{min}^{-1}\end{array}$ & $\begin{array}{c}\text { Transmission } \\
\text { ratio }\end{array}$ \\
\hline S1 & $0-0.97$ & $0-77.43$ & 36.16 \\
S2 & $0-1.57$ & $0-124.72$ & 22.45 \\
S3 & $0-2.07$ & $0-165.05$ & 16.97 \\
\hline
\end{tabular}

Based on the internal gear combination and principle of UBS gearbox, the three forward stalls gear train and drive shaft 
combination of UBS gearbox is shown in Figure 4. There were three forward states (three forward stalls, named S1 stall, S2 stall, and S3 stall). The forward velocity of S1 stall, S2 stall and S3 stall were determined by the shift shaft and gear. The straight driving and braking were achieved by clutching gear shaft.

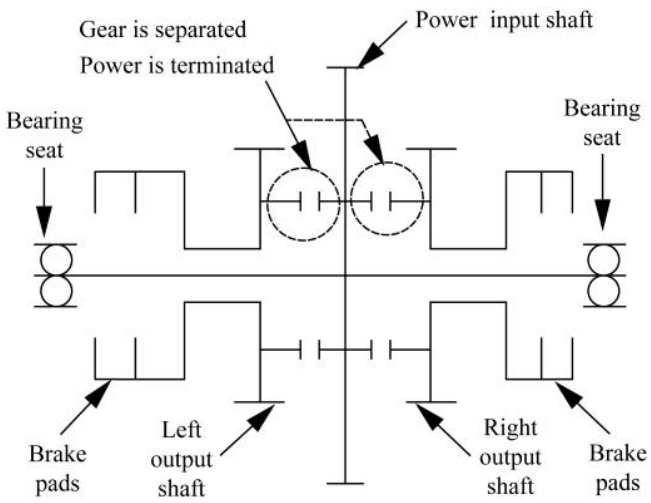

Figure 4 Gear train and drive shaft combination of UBS gearbox

According to Figures 3 and 4, there were two brake pads to break the left or right output shaft. The left or right output shaft also could separate from the power input shaft. The straight driving of the crawler was achieved by crawler shaft VII (crawler $\mathrm{R}$ ), or crawler shaft VIII (crawler L). If the forward crawler needs to be sudden braked, the brake shaft and gear (VI) could achieve this function by manual operation.

\subsection{In-situ steering principle}

Based on the internal gear combination and principle of the UBS gearbox, the PNS gearbox was designed. The gear train and drive shaft combination of the PNS gearbox is shown in Figure 5.

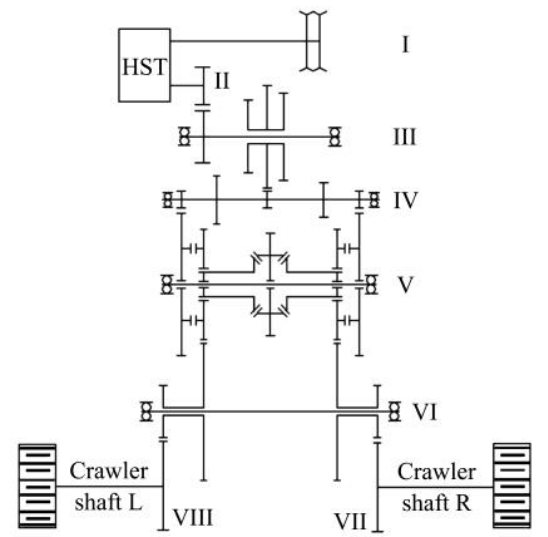

a. Gear train and shaft combination

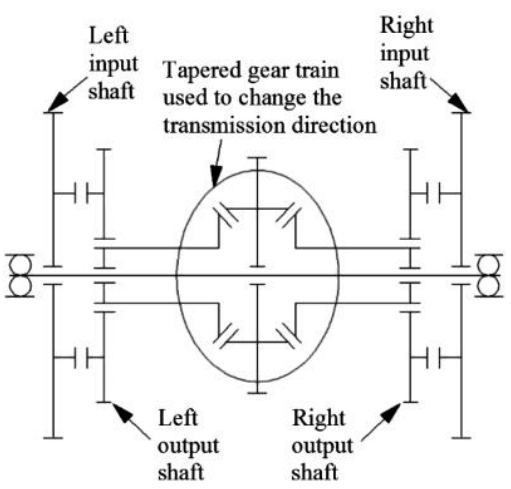

b. PNS gears and shaft principle

Figure 5 Gear train and drive shaft combination of PNS gearbox

For adapting installation and construction dimensions of existing combine harvester gearbox, dimensions of the PNS gearbox was similar to the UBS gearbox. In this way, the PNS gearbox could replace the UBS gearbox on existing crawler combine harvester. According to Figure 5a, the internal gear combination and principle of PNS gearbox were generally similar to UBS gearbox. However, the important difference between them was that PNS gears and shaft replaced the clutch gear and shaft.

In order to show the gear combination and principle, the PNS gears combination is shown in Figure $5 \mathrm{~b}$. There were two input/output shafts (Left input shaft and right input shaft) to obtain/transmit the power from idler shaft and gear.

When the power was transmitted to crawler shaft, the crawler shaft and crawler $\mathrm{R}$ or crawler $\mathrm{L}$ would transmit power to drive wheel. The crawler was driven by the drive wheel. The composition of the crawler drive and forward is shown in Figure 6.

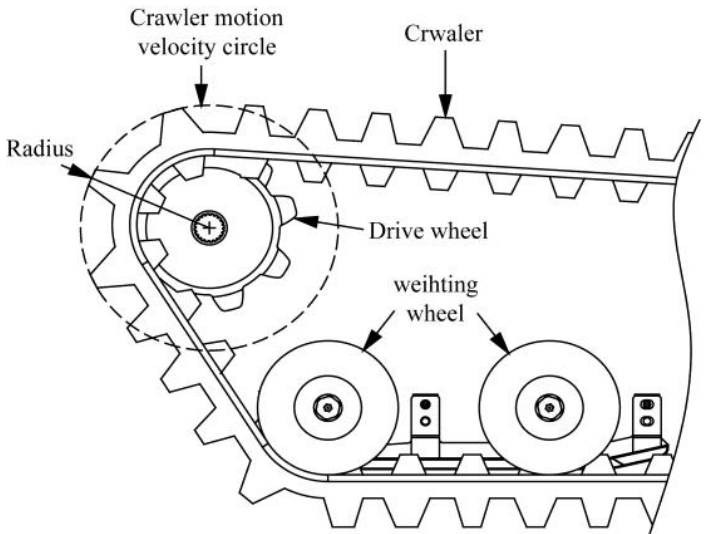

Figure 6 Schematic of crawler and drive wheel

According to Figure 6, the crawler forward velocity was harvesting forward velocity. The radius, speed, torque and power of transmission shaft could be calculated by the designed crawler forward velocity. Thus, the crawler motion velocity circle was the basic condition. The crawler motion was driven by the drive wheel.

Crawler rolling tracks were marked by crawler center groove, which is shown in Figure 7.

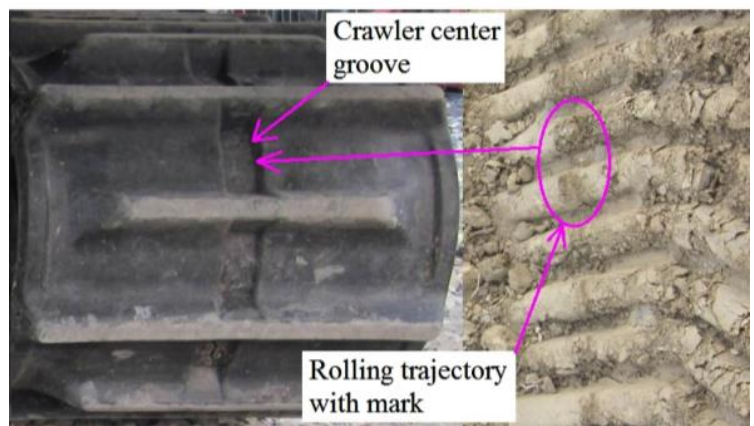

Figure 7 Crawler center groove mark

The mass of the combine harvester prototype was $3060 \mathrm{~kg}$. Crawler center distance, crawler grounding, crawler width were $1150 \mathrm{~mm}, 1620 \mathrm{~mm}, 450 \mathrm{~mm}$, respectively. The ladder shape track bead pitch was $70 \mathrm{~mm}$.

\subsection{Steering method and track}

There were three types of power transmission mode by PNS gearbox.

(1) The first kind was that left input shaft got power and transmitted power to left output shaft. At the same time the right input shaft got power and transmitted power to right output shaft. Then crawler went straight forward.

(2) The second one was that left input shaft got power and transmitted power to left output shaft. Right input shaft got and 
transmits power to right output shaft. But left (or right) output shaft was separated from the idler shaft and gear. Then power was transmitted from left (or right) output shaft to right (or left) output shaft with the big gear was brake.

The rotation direction was changed by two sets of gears. Rotation direction between left output shaft and right output shaft was reversed. The power transmission mode of PNS is shown in Figure 8 .

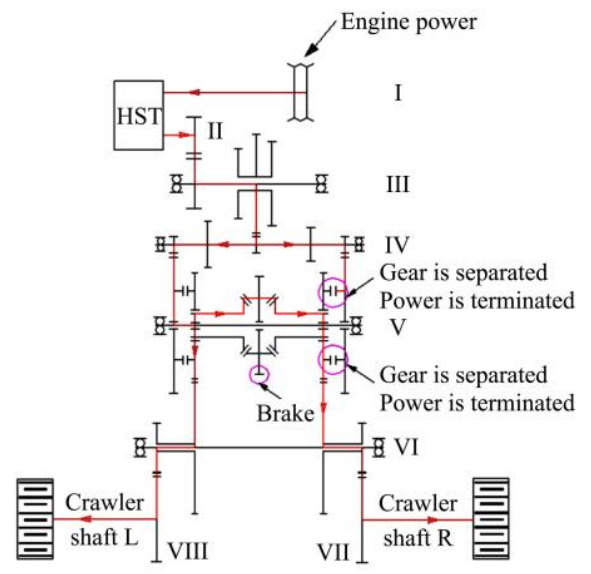

Figure 8 Power transmission mode of PNS

(3) The third type was that left (or right) input shaft got power and transmitted power to left (or right) output shaft. But the right (or left) input shaft was brake. Then only one input shaft (left or right) gained power and transmitted power while another input shaft was braking. That means one side of crawlers could be rotated by gaining power, but another side was brake. Then the crawler was unilateral brake steering.

\subsection{Steering gearbox parameters}

When crawler combine harvester was harvesting in field, the harvesting speed was three states (Named S1 stall, S2 stall, S3 stall). The max forward velocity of S1 stall, S2 stall and S3 stall were about $1 \mathrm{~m} / \mathrm{s}, 1.5 \mathrm{~m} / \mathrm{s}$ and $2 \mathrm{~m} / \mathrm{s}$, respectively. Because the maximum power consumption of left crawler shaft $\mathrm{L}$ and right crawler shaft $\mathrm{R}$ was $23 \mathrm{~kW}$ (the power consumption was tested in reference [19]).

Based on the results of the structure and principle of the PNS gearbox, the 3D model was developed by Pro/E software. The 3D model of the PNS gearbox is shown in Figure 9.

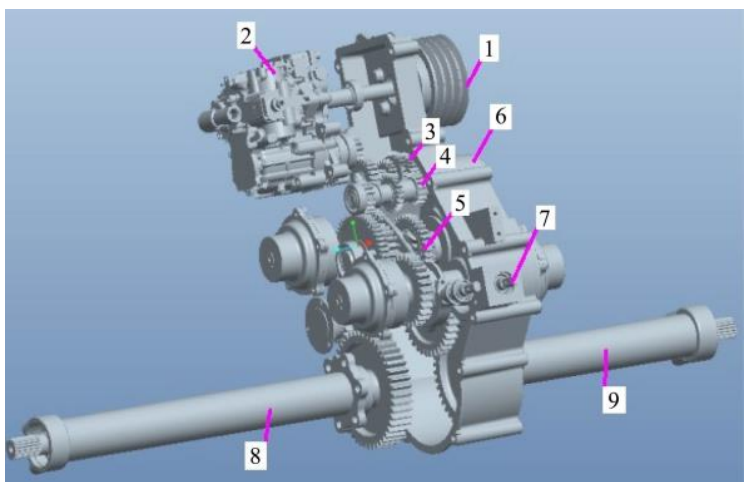

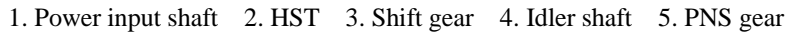
6. Gearbox 7. Shift lever 8. Left drive shaft 9. Right drive shaft

Figure 9 Diagram 3D model of PNS gearbox

The shift gear train and PNS gear system are key components of steering gearbox. The shift fork shifts the three stalls gears for speed adjustment. The gears on shift shaft could axially slide. The brake shaft is used to shake the PNS gears. The steering gear and clutch shaft of gear are contacted by a shift board. In addition, clutch shaft could be controlled by clutch shift fork. So the PNS gears could be separated or engaged by controlling the clutch shift fork. PNS gears can achieve three steering modes, such as straight forward, UBS, and PNS in situ.

\subsection{Steering soil characteristics test}

Steering soil characteristics were tested by TJSD-750 soil compactness tester (produced by Zhejiang Top Instrument Co., Ltd.). The TJSD-750 soil compactness tester is shown in Figure 10a. The test depth of the compacted soil is $30 \mathrm{~cm}$, which is shown in Figure 10b.

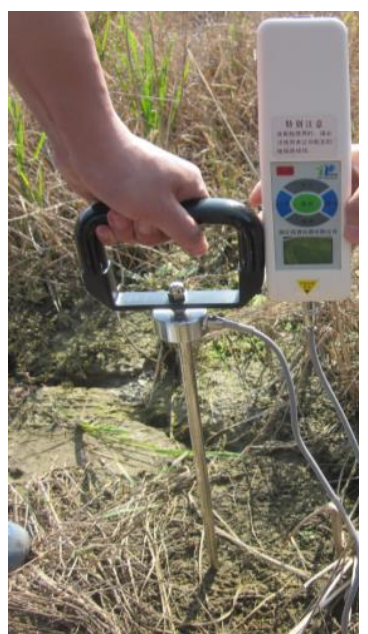

a. Soil thickness

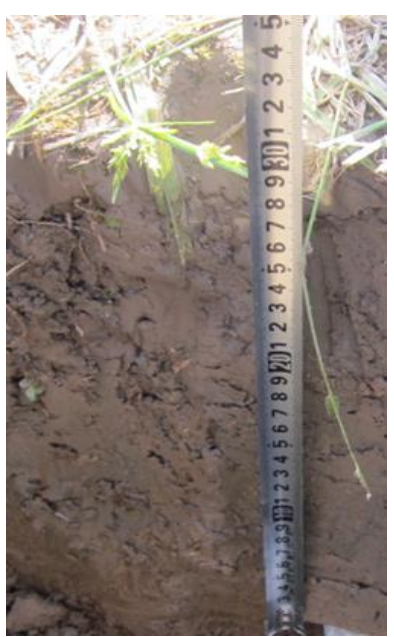

b. Firmness test
Figure 10 Steering soil firmness test

TJSD-750 soil compactness tester can be used to measure and display soil compaction in real time. When connected with the computer, it can automatically generate a soil compactness curve for each measurement point. The measured depth is $0-450 \mathrm{~mm}$. The measurement range is $0-100 \mathrm{~kg}$. The measurement accuracy is $0.05 \mathrm{~kg}$.

Paddy soil firmness parameters are shown in Table 2.

Table 2 Soil firmness parameter

\begin{tabular}{ccccc}
\hline \multirow{2}{*}{$\begin{array}{c}\text { Thickness } \\
\text { /cm }\end{array}$} & \multicolumn{4}{c}{ Firmness pressure of soil $/ \mathrm{kg} \cdot \mathrm{cm}^{-2}$} \\
\cline { 2 - 5 } & Dry soil 1 & Dry soil 2 & Field soil 1 & Field soil 2 \\
\hline 5 & 6.15 & 5.38 & 5.81 & 5.22 \\
10 & 11.39 & 12.78 & 12.22 & 12.75 \\
15 & 15.57 & 15.75 & 15.35 & 16.31 \\
20 & 19.73 & 16.98 & 18.63 & 19.75 \\
25 & 18.82 & 19.05 & 21.37 & 17.59 \\
30 & 33.44 & 27.59 & 16.58 & 15.24 \\
\hline
\end{tabular}

\section{Results and Discussion}

\subsection{PNS gearbox}

Based on the above results, the PNS gears were manufactured. The PNS gearbox was assembled and installed by bulk parts, and physical of overall assembly structure is shown in Figure 11.

\subsection{Physical prototype of PNS gearbox}

The PNS gearbox was installed on a crawler combine harvester. Rice cutting and conveying devices have been removed for more intuitive to watch the test process. The physical prototype of the PNS gearbox is shown in Figure 12.

\subsection{Steering performance analysis}

In order to test and compare crawler combine harvester steering performance between PNS and UBS pattern, the crawler 
rolling tracks and traces of two types of steering gearbox on dry soil are shown in Figure 13. The crawler rolling tracks and trajectory of PNS are shown in Figure 13a and the crawler rolling tracks and trajectory of the UBS is shown in Figure 13b.

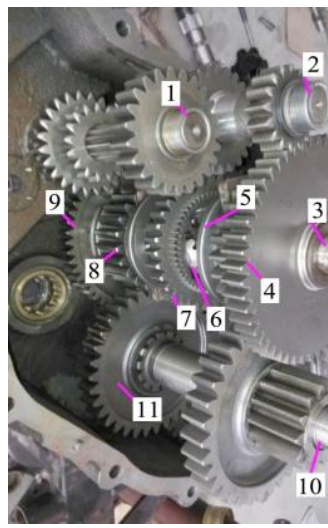

1. Shift gear with three stalls 2. Idler shaft 3. PNS shaft 4. Power input shaft of steering gears 5. Cone gear I for change rotation direction 6 . Cone gear II for change rotation direction 7. Brake gear 8. Power output shaft of steering gears 9. Power input shaft of steering gears 10. Brake shaft of steering gears 11. Drive shaft gear.

Figure 11 Internal gear transmission assembly structure of PNS gearbox

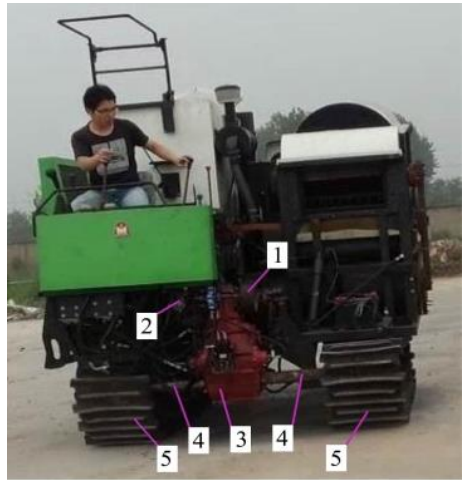

1. Power input belt from Engine 2. Hydraulic static transmission (HST)

3. Steering gearbox 4. Drive shaft of crawler 5. Crawler

Figure 12 Physical prototype of PNS gearbox

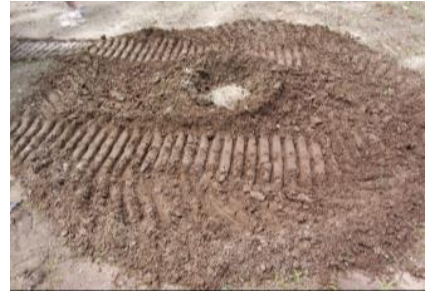

a. Trajectory of PNS

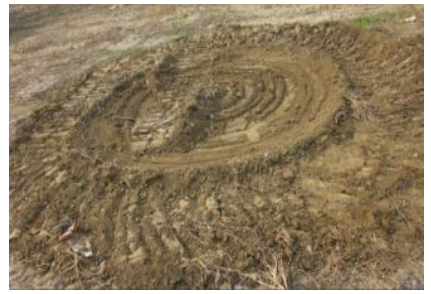

b. Trajectory of UBS
Figure 13 Crawler rolling tracks and trajectory of two types of steering gearbox on dry soil

According to Figure 13a, the process of machinery compaction, soil cut depth reflected the soil compaction degree ${ }^{[20]}$. The rolling trace of the PNS was slight. There were not any cutting traces, but some obstructing soil was produced. A typical feature was that a blank area without rolling formed. The rolling area was a ring. In Figure 13b, a seriously cutting trace was produced by the crawler of UBS. The obstructing soil was accumulated along a big cycle. The deep pit $35 \mathrm{~cm}$ was produced by the brake crawler, which produced serious damage to the soil layer. To some extent, machinery compaction had a remarkable effect on soil compaction.

In addition, the physical property of soil was severely destroyed by the brake crawler, which resulted in soil clay or hardening. Therefore, the type of construction machinery and times of compaction must be controlled in land reclamation. Different compact machines of varied weights and ground contact areas would lead to different compaction effects. The dump truck crushed down into $30 \mathrm{~cm}$ on the upper layer, which realized the maximum compaction after five times of compaction ${ }^{[21]}$. While the crawler dozer needed seven times for the same outcome.

The crawler straight forward was well known ${ }^{[22,23]}$, while the steering trajectory of PNS in situ was not known well. Based on the steering mechanism and principle, the steering trajectory of UBS is shown in Figure 14a, the steering trajectory of PNS is shown in Figure 14b.

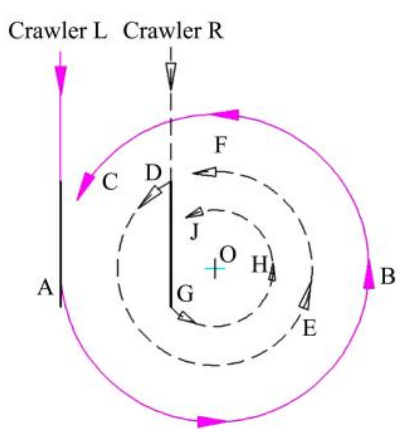

a. Trajectory of UBS

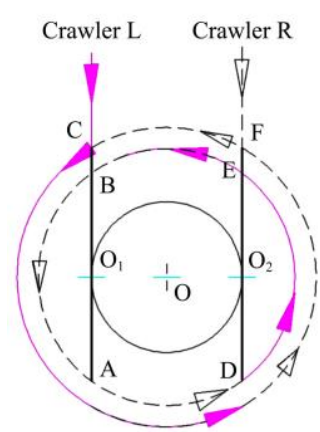

b. Trajectory of PNS

Figure 14 Steering trajectory of crawler chassis with UBS or PNS

According to Figure 14, the crawler L (Left crawler) is shown as a solid line. Crawler R (Right crawler) is shown as a dotted line. Crawler $\mathrm{L}$ was forward along the arc $\mathrm{ABC}$, but crawler $\mathrm{R}$ was brake with sliding area between arc DEF and arc GHJ. So the brake crawler was sliding with a big ring area. According to Figure $14 \mathrm{~b}$, the crawler L and crawler R were PNS. When the PNS rotated a circle, only a ring area existed. Intermediate area of a circle was no sliding or rolling by the crawler. Comparing sliding or rolling area with two types of steering gearbox, the sliding or rolling area of PNS was lesser, without rolling area.

Some researchers have done investigations of steering and gearbox. Iida et al reported the turning performance of an articulated vehicle in which applying direct yaw-moment control was applied to reduce the turning radius ${ }^{[24]}$. Soft ground with low moisture has the property of low viscosity and high friction. Track stress distribution played an important role in the areas of track mechanism design and optimizing. To improve the passing capacity of the track and to reduce the slip on the ground, the ration between track ground length and track center distance less than 1.7 was necessary for steering of tracked vehicles and steering ability was better ${ }^{[25]}$.

Different compaction times had different depth influences and degrees on soil compaction ${ }^{[26]}$. Initial compaction was most obvious on soil compaction. Single compaction effect on soil compaction would be gradually reduced when the times of compaction were increased in a certain range. A continuous increase of compaction times enforced lower layer compaction though, yet crawls slowly upward. Repeated single compaction of small pressure on soil indeed cannot be ignored.

\subsection{Steering performance test}

Crawler center rolling trajectory was a crawler canter groove. For drawing the crawler rolling tracks and traces, the center point was chosen. On the crawler rolling tracks, 24 points (each point corresponds to a center angle of $15^{\circ}$ ) were chosen on the circumference. The crawler center rolling trajectory radius of 24 points were tested (The average results were post-hoc test at the $5 \%$ 
significance level). The un-rolling center point was selected as the midpoint. The test results are shown in Table 3.

Table 3 Crawler center rolling trajectory radius

\begin{tabular}{|c|c|c|c|c|}
\hline \multirow{2}{*}{$\begin{array}{c}\text { Test } \\
\text { point } \\
\text { No. }\end{array}$} & \multicolumn{2}{|c|}{ Trajectory radius of PNS/mm } & \multicolumn{2}{|c|}{ Trajectory radius of UBS $/ \mathrm{mm}$} \\
\hline & Outer ring & Inner ring & Outer ring & Inner ring \\
\hline 1 & 1175 & 159 & 2310 & 951 \\
\hline 2 & 1050 & 177 & 2287 & 909 \\
\hline 3 & 1086 & 186 & 2150 & 858 \\
\hline 4 & 1084 & 204 & 2270 & 926 \\
\hline 5 & 1210 & 229 & 2320 & 881 \\
\hline 6 & 1170 & 238 & 2166 & 868 \\
\hline 7 & 1270 & 282 & 2010 & 765 \\
\hline 8 & 1389 & 338 & 1939 & 726 \\
\hline 9 & 1444 & 381 & 1999 & 770 \\
\hline 10 & 1470 & 437 & 1986 & 746 \\
\hline 11 & 1526 & 469 & 2139 & 683 \\
\hline 12 & 1519 & 509 & 2121 & 701 \\
\hline 13 & 1450 & 507 & 2080 & 643 \\
\hline 14 & 1500 & 463 & 2098 & 627 \\
\hline 15 & 1380 & 437 & 1994 & 620 \\
\hline 16 & 1293 & 382 & 1981 & 672 \\
\hline 17 & 1390 & 351 & 2086 & 661 \\
\hline 18 & 1280 & 296 & 2060 & 783 \\
\hline 19 & 1180 & 266 & 2078 & 812 \\
\hline 20 & 1288 & 239 & 2046 & 750 \\
\hline 21 & 1107 & 211 & 2064 & 838 \\
\hline 22 & 1136 & 183 & 2072 & 827 \\
\hline 23 & 1189 & 178 & 2236 & 854 \\
\hline 24 & 1214 & 174 & 2155 & 914 \\
\hline
\end{tabular}

Based on the results of Table 3, the crawler rolling tracks and traces of PNS and UBS were drawn. The crawler center groove mark would produce a rolling trajectory with mark. Crawler rolling tracks and traces of PNS and UBS are shown in Figure 15 and Figure 16.

According to Figure 15 , if the crawler steering $360^{\circ}$, the rolling trajectory radius of PNS was ring area. The outer diameter and inner diameter of ring area were $2.69 \mathrm{~m}$ and $0.68 \mathrm{~m}$, respectively. Then the rolling area was $5.37 \mathrm{~m}^{2}$, but there was a non-shaving area of $0.36 \mathrm{~m}^{2}$.

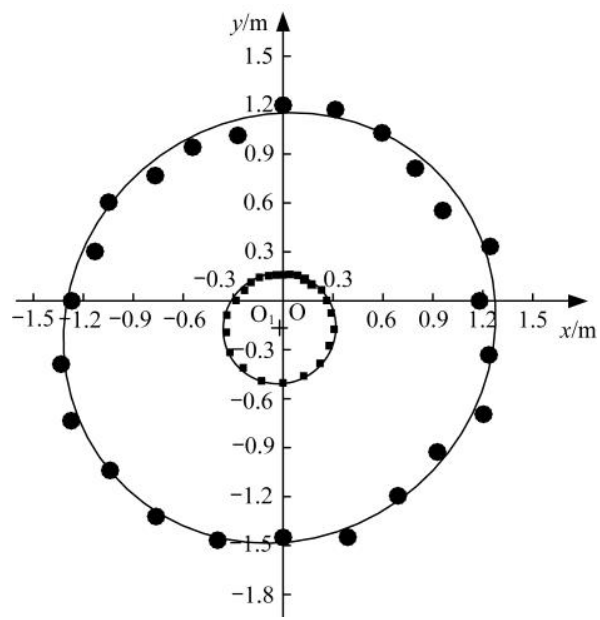

Figure 15 Crawler rolling trajectory of PNS

According to Figure 16, if the crawler steered $360^{\circ}$ with UBS, the rolling trajectory diameter was $4.22 \mathrm{~m}$, with a cut soil diameter $1.56 \mathrm{~m}$. Then the rolling area and the shaving area were $13.92 \mathrm{~m}^{2}$ and $1.88 \mathrm{~m}^{2}$, respectively. The rolling area and shaving area of PNS was lesser $8.55 \mathrm{~m}^{2}$ than that of UBS. Steering type of PNS was better than that of the UBS type. The dotted circle was the theoretical value. The true center points of PNS and UBS were different from the chosen center of the circle. The coordinate value of PNS was $(-22.9,166.0)$, which was $167.5 \mathrm{~mm}$ from the chosen center. The true center point of UBS was (37.0, 121.0), which was $126.1 \mathrm{~mm}$ from the chosen center.

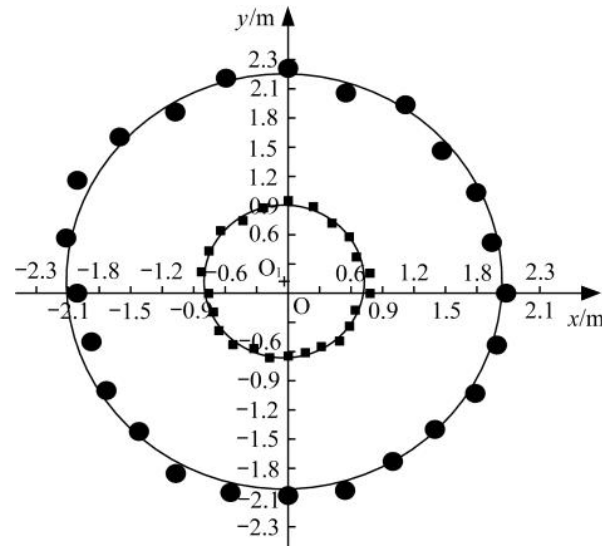

Figure 16 Crawler rolling trajectory of UBS

According to Figure 15 and Figure 16, the measured value did not fall entirely on the theoretical circle. The error comes from the measurement error and the drift error of machine vibration. A kinematic model based on the instantaneous steering center was developed by studying the interaction of track and ground ${ }^{[27]}$. Real tests showed that the position errors predicted using this method was reduced by more than $30 \%$ compared to the traditional trajectory prediction method. Chi et al. ${ }^{[28]}$ studied the steering performance of tracked vehicle adopting differential steering mechanism. He indicated that the turning radius was reduced from $1.00 \mathrm{~m}$ to $0.29 \mathrm{~m}$. Experiment results showed that steering power ratio increases as experimental turning radius decreases when tracked experimental prototype being steered on soft terrain. A small high clearance tracked vehicle with a full hydraulic drive was designed by Wang et al. ${ }^{[29]}$ The pivot steering trajectories radius variation coefficients were $40.97 \%$ to $64.89 \%$. With the increasing of ground parameters, the corresponding lateral deviation value was increasing under the structure parameters of tracked vehicles for setting value.

\subsection{Steering effects on rice field}

Because field soil was high moisture, there were some soil damage and crawler sink. In order to compare the steering performance of the PNS gearbox and UBS gearbox, two steering patterns were compared in rice field. The destruction form of rice field soil by steering is shown in Figure 17.

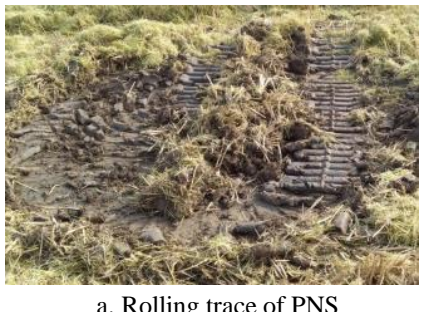

a. Rolling trace of PNS

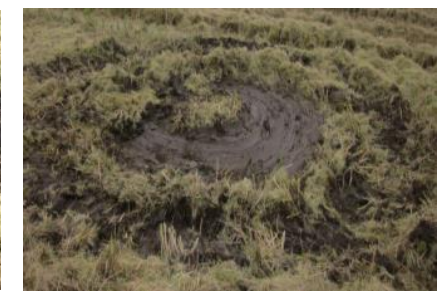

b. Rolling trace of UBS
Figure 17 Destruction form of rice field soil

According to Figure 17, The PNS had only minor damage to the paddy soil. But the soil was overturned by UBS. In the process of machinery compaction, the soil compaction in different layers did not remain the same. When the soil was less 
compacted, the upper layer would experience a skyrocketing soil compaction. When times of compaction were increased, the soil compaction difference between each layer narrows. The mid-layer $(>20-30 \mathrm{~cm}$ ) features a comparatively high compaction under upward and downward stress. The results of rice field destruction form show that the steering performance of PNS is better than that of UBS. The straight forward and steering in situ performance designed in this paper achieves the expected results.

\section{Conclusions}

(1) This paper developed a PNS gearbox crawler, which could achieve three operating modes, such as straight forward, unilateral brake steering, and positive and negative steering in situ. The PNS steering in situ was smooth and without soil cutting phenomenon.

(2) The rolling trajectory radius of the PNS crawler was ring area where the outer diameter and the inner diameter of the ring area were $2.69 \mathrm{~m}$ and $0.68 \mathrm{~m}$, respectively. The rolling area and the scratch free area produced by PNS were $5.37 \mathrm{~m}^{2}$ and $0.36 \mathrm{~m}^{2}$ while the rolling area and the scratch free area produced by the UBS crawler were $13.92 \mathrm{~m}^{2}$ and $1.88 \mathrm{~m}^{2}$, respectively, which was $8.55 \mathrm{~m}^{2}$ larger than that produced by PNS.

\section{Acknowledgements}

This research work was supported by the National Natural Science Foundation of China (51705212), Natural Science Foundation of Jiangsu Province (BK20170553), Jiangsu Province "Six Talents Peak" High-level Talent Project (GDZB-085), Open Fund of Jiangsu Key Laboratory of Agricultural Equipment and Intelligent High Technology (JNZ201912) and A Project Funded by the Priority Academic Program Development of Jiangsu Higher Education Institutions (PAPD-2018-87).

\section{[References]}

[1] Fu W, Zhang Z Y, Ding K, Cao W B, Kan Z, Pan J B, et al. Design and test of 4ZZ-4A2 full-hydraulic self-propelled jujube harvester. Int J Agric \& Biol Eng, 2018; 11(4): 104-110.

[2] Li L Q, Wang D F, Yang X. Study on round rice straw bale wrapping silage technology and facilities. Int J Agric \& Biol Eng, 2018; 11(4): $88-95$.

[3] Seegmiller N, Rogers-Marcovitz F, Miller G. Vehicle model identification by integrated prediction error minimization. International Journal of Robotics Research, 2013; 32 (32): 912-931.

[4] Rafael R. Sola-Guirado, Gregorio L. Blanco-Roldan, Sergio Castro-Garcia, F.J. Castillo-Ruiz, Jesus A. Gil-Ribes. Innovative circular path harvester for mechanical harvesting of irregular and large-canopy olive trees. Int $\mathrm{J}$ Agric \& Biol Eng, 2018; 11(3): 86-93.

[5] Dong C, Cheng K, Hua W, Ou Y, Wu B. Steering performance analysis of articulated tracked vehicle considering soil shear defomation. Journal of Jilin University, 2016; 46(6): 1921-1932. (in Chinese)

[6] Chi Y, Shi D, Wang H, Zhang R. Research on actual steering power ratio of differential steering mechanism of tracked vehicle on soft ground. Transactions of the CSAE, 2014; 30(21): 32-39. (in Chinese)

[7] Zhang W, Min X, Sun X. Effect of different machinery and compaction on the physical property of reclamation soil in coal area. Shandong Land and Resources, 2017; 33(3): 64-72.

[8] Li J, Wang H, Rui Q. Analysis and testing verification the steady state steering performance of tracked vehicle. Mechanical Engineer, 2016; 1: 82-85.

[9] Zhou H, Zhang J, Xia J, Tahir H M, Zhu Y, Zhang C. Effects of subsoiling on working quality and total power consumption of high stubble straw returning machine. Int J Agric \& Biol Eng, 2019; 12(4): 56-62.

[10] Lyasko M. Slip sinkage effect in soil-vehicle mechanics. Journal of Terramechanics, 2010; 47(1): 21-31

[11] Wang H, Chen B, Rui Q, Guo J, Shi L. Analysis and experiment of steady-state steering of tracked vehicle under concentrated load. Acta Armamentarii, 2016; 37(12): 2196-2204

[12] Al-milli S, Seneviratne L D, Althoefer K. Track-terrain modelling and traversability prediction for tracked vehicles on soft terrain. Journal of Terramechanics, 2010; 47(3): 151-160.

[13] Liu Z, Lü Z, Zheng W, Zhang W, Cheng X. Design of obstacle avoidance controller for agricultural tractor based on ROS. Int J Agric \& Biol Eng, 2019; 12(6): 58-65.

[14] Du Y, Gao J, Jiang L. Numerical analysis on the adhesion property of rigid track on. Chinese Journal of Computational Mechanics, 2017; 34(3) 384-389.

[15] Chi Y, Jiang E. Experiment on steering power ratio of tracked vehicles adopting new differential steering mechanism. Transactions of the CSAM 2008; 39(8): 44-53. (in Chinese)

[16] Rahman A, Yahya A, Zohadie M. Simulated steerability of a segmented rubber tracked vehicle during turning on sepang peat terrain in Malaysia. International Journal of Heavy Vehicle Systems, 2005; 12(2): 139-168.

[17] Chen Z, Zhao G, Zhai L, Tong S. Pivot steering control and D2P real-time simulation for electric tracked vehicle. Journal of Northeastern University (Natural Science), 2013; 34(1): 114-117. (in Chinese)

[18] Li Y M, Chen J S, Liang Z W, Ma X, Jiang X C. Design and Experiment of Differential Steering Mechanism for Track Combine Harvester. Transactions of the CSAM, 2016; 47(7): 127-135. (in Chinese)

[19] Tang Z, Li Y, Wang R, Chen J. Experimental study of multi-source dynamic load of combine harvester in rice harvesting. International Agricultural Engineering Journal, 2016; 25(3): 46-52.

[20] Liu L H, Fei L J, Zhu H Y. Effects of water temperature on soil water infiltration characteristics under drip irrigation. Journal of Drainage and Irrigation Machinery Engineering (JDIME), 2019; 37(2): 166-173.

[21] Liu N, Li X, Guo B. Simulation analysis on influencing factors of reclamation soil compaction in mechanical compaction process. Transactions of the CSAE, 2014; 30(1): 183-190. (in Chinese)

[22] Raymond J B, Jayakumar P. The shearing edge of tracked vehicle-Soil interactions in path clearing applications utilizing Multi-Body Dynamics modeling \& simulation. Journal of Terramechanics, 2015; 58: 39-50.

[23] Luo E, Feng J, Zhang M, Ma J. Pivot steering characteristics of tracked vehicle based on skid condition. Journal of Agricultural Mechanization Research, 2013; 76(2): 277-283. (in Chinese)

[24] Iida M, Nakashima H, Tomiyama H, Oh T, Nakamura T. Small-radius turning performance of an articulated vehicle by direct yaw moment control. Computers \& Electronics in Agriculture, 2011; 76(2): 277-283.

[25] Chen Z, Luo C. Pivot turing ability research of large hydraulic crawler Jumbo. Journal of Jinggangshan University (Natural Science), 2015; 36(2): 54-59. (in Chinese)

[26] Xu C L, Hou S N, Yao Z D, Zhang F, She D L. Spatial variability and scale effect of soil bulk density of farm land in South China. Journal of drainage and irrigation machinery engineering (JDIME), 2017; 35(5): 424-429. (in Chinese)

[27] Xiong G, Lu H, Guo K, Chen H. Research on trajectory prediction of tracked vehicles based on real time slip estimation. Acta Armamentarii, 2017; 38(3): 600-607.

[28] Chi Y, Zhang R, Ren J, Li H, Wang Y. Steering power ratio affected by soil sinkage with differential steering in tracked vehicle. Transactions of the CSAE, 2016; 32(17): 62-68. (in Chinese)

[29] Wang B, Wang M, wang W, Chong D. Steering performance test of high clearance tracked vehicle. Journal of Henan Agricultural University, 2017; 51(3): 335-340. (in Chinese) 